\title{
Supporting information: Synthesis and Properties of Nanostructured Tungsten Oxide on Au(111)
}

\author{
Rishav Harsh, ${ }^{\dagger}$ Mariem Ben Youssef, ${ }^{\ddagger}$ Cyril Chacon ${ }^{\dagger}{ }^{\text {Vincent Repain }},{ }^{\dagger}$ Amandine

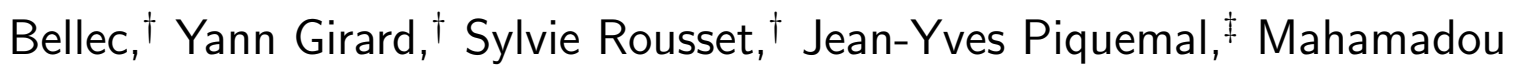 \\ Seydou, ${ }^{\ddagger}$ Philippe Decorse, ${ }^{\ddagger}$ Philippe Lang, ${ }^{*}, \ddagger$ and Jérôme Lagoute ${ }^{*, \dagger}$ \\ †Université de Paris, Laboratoire Matériaux et Phénomènes Quantiques, CNRS, F-75013, \\ Paris, France \\ $\ddagger$ Universit de Paris, ITODYS, CNRS, UMR 7086, 15 rue Jean-Antoine de Baïf, 75205 \\ Paris Cedex 13, France.
}

E-mail: lang@univ-paris-diderot.fr; jerome.lagoute@univ-paris-diderot.fr

We present here some characteristics of i) the transformation of thick films of precursors into $\mathrm{WO}_{3}$ oxide films with different annealing temperatures by infra red spectroscopy ii) the structure of $\mathrm{WO}_{3}$ oxide films of different thicknesses analyzed by X-ray diffraction (XRD).

\section{XPS tables of $\mathrm{WO}_{3}$ thin film on $\mathrm{Au}$}

Hereafter are given the XPS tables of a $\mathrm{WO}_{3}$ film deposited on $\mathrm{Au}$ with the peroxo precursor method; $\mathrm{A} 1$ and $\mathrm{A} 2$ correspond to $\mathrm{W}(6)$ and $\mathrm{B} 1, \mathrm{~B} 2$ to $\mathrm{W}(5)$. 
General Peak Table:

\begin{tabular}{|l|c|c|c|c|}
\hline Name & Peak BE & FWHM eV & Area (P) CPS.eV & Atomic \% \\
\hline Au 4f & 84.00 & 0.79 & 215584.11 & 4.86 \\
\hline C 1s & 284.95 & 1.71 & 47120.82 & 24.84 \\
\hline O 1s & 530.68 & 1.50 & 254557.28 & 55.45 \\
\hline W 4f & 35.84 & 1.38 & 360530.72 & 14.85 \\
\hline
\end{tabular}

Peak table W4f after deconvolution :

\begin{tabular}{|c|c|c|c|c|}
\hline Name & Peak BE & FWHM eV & Area (P) CPS.eV & Atomic $\%$ \\
\hline $\mathrm{W} 4 \mathrm{f}_{7 / 2} \mathrm{~A} 1$ & 35.83 & 1.27 & 191732.64 & 52.71 \\
\hline $\mathrm{W}_{4 \mathrm{f}_{5 / 2}} \mathrm{~A} 2$ & 37.95 & 1.27 & 141765.71 & 39.02 \\
\hline $\mathrm{W} 4 \mathrm{f}_{7 / 2} \mathrm{~B} 1$ & 34.53 & 0.92 & 17479.23 & 4.80 \\
\hline $\mathrm{W} 4 \mathrm{f}_{5 / 2} \mathrm{~B} 2$ & 36.85 & 0.80 & 12587.55 & 3.46 \\
\hline
\end{tabular}

\section{Polarization modulation-infrared reflection-adsorption spectroscopy (PM-IRRAS)}

The $\mathrm{WO}_{3}$ oxide film formation is followed by IR spectroscopy accordingly to the reaction :

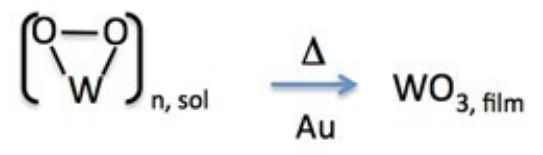

After deposition of the precursor solution on $\mathrm{Au}$, the annealing of precursor film on $\mathrm{Au}$ is carried out from 80 to $450^{\circ} \mathrm{C}$. When the annealing temperature increases, we observe the decrease of the bands due to the moiety $(\mathrm{O}=\mathrm{W}-\mathrm{O}-\mathrm{O}-)$, i.e. those $\nu(\mathrm{W}-\mathrm{O})$ at $976 \mathrm{~cm}^{-1}$ and $\nu(\mathrm{W}-\mathrm{O}-\mathrm{O})$ at $930 \mathrm{~cm}^{-1}$ (see Taylor et al. ${ }^{1}$ and references therein), and the one (OH, W-O) at $1430 \mathrm{~cm}^{-1}(\delta \mathrm{OH}+\nu \mathrm{W}-\mathrm{O})$. The decomposition of peroxo groups gives oxo ones and some new bands $(\nu \mathrm{W}-\mathrm{O})$ appear at $980 \mathrm{~cm}^{-1}$ (very strong, $\mathrm{W}=\mathrm{O}, \mathrm{W}-\mathrm{O}$ ), $863 \mathrm{~cm}^{-1}$ (shoulder, 
$\left.\mathrm{W}_{3} \mathrm{O}_{9}\right), 795 \mathrm{~cm}^{-1}(\mathrm{~W}-\mathrm{O}-\mathrm{W})$ and one at $710 \mathrm{~cm}^{-1}(\gamma \mathrm{W}-\mathrm{O}-\mathrm{W}) .{ }^{2}$ The evolution of the IR spectrum shows that, upon annealing, the precursor disappear at the same time the $\mathrm{WO}_{3}$ oxide is formed.

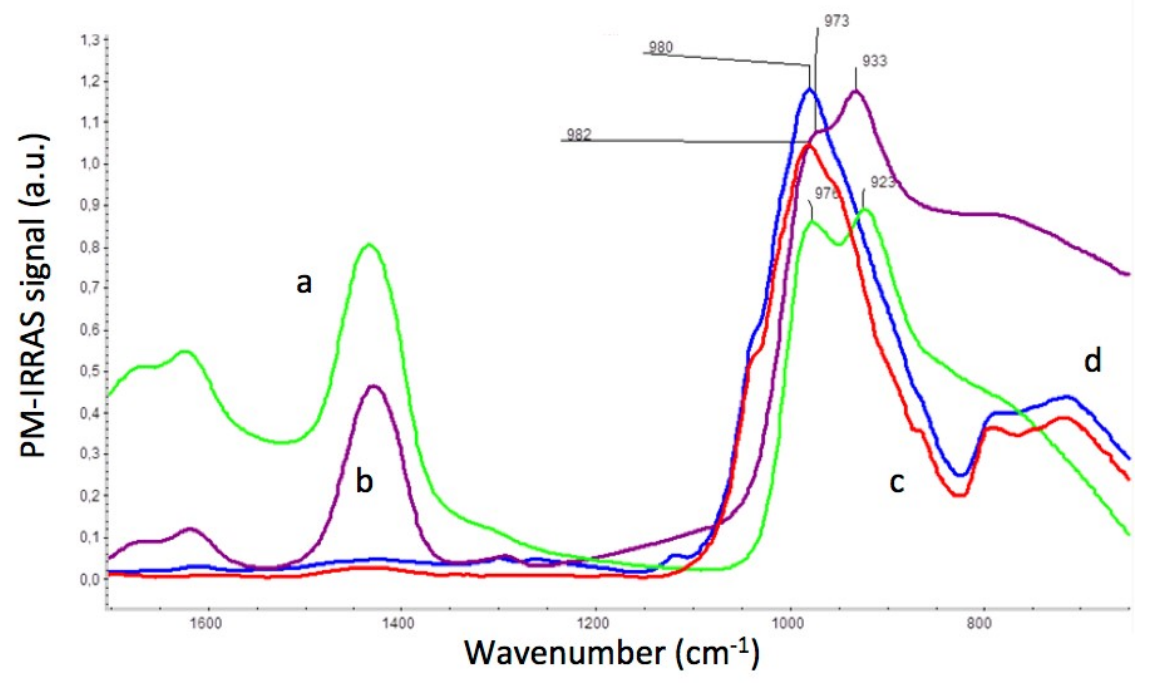

Figure S 1: PM-IRRAS spectra of film of precursor solution $\mathrm{WO}_{3}-\mathrm{H}_{2} \mathrm{O}_{2}$ deposited on $\mathrm{Au}(111)$ and annealed at (a) $80^{\circ} \mathrm{C}$; (b) $150^{\circ} \mathrm{C}$; (c) $300^{\circ} \mathrm{C}$; (d) $450^{\circ} \mathrm{C}$. 


\section{XRD characterization}

We follow by XRD the orientation of $\mathrm{WO}_{3}$ films of different thicknesses deposited onto $\mathrm{Au}$ and annealed at $350^{\circ} \mathrm{C}$. The $\mathrm{WO}_{3}$ films on $\mathrm{Au}(111)$ are likely a mixture of monoclinic (M) and hexagonal (H). ${ }^{3,4}$ The thickest $\mathrm{WO}_{3}$ films are oriented with their plane (200) perpendicular to the substrate (for monoclinic) whereas the $50 \mathrm{~nm}$ thick film is not; it may be either isotropic or oriented with its plane (111) (for monoclinic) parallel to the substrate since the ratio of peaks (200), (020) and (002) are identical to those of the $\mathrm{WO}_{3}$ isotropic bulk film. The latter hypothesis is in agreement with STM images for very thin films. Note that

the X-ray pattern of the $50 \mathrm{~nm}$ thick film suggests that we observe the plane (200) of the structure (H) but not its plane (001). The plane (200) is therefore parallel to the substrate. But the presence of the plane (200) of a film (H) in the STM image (S2) can be ruled out. We thus confirm that only monoclinic structure is observed in STM images. 


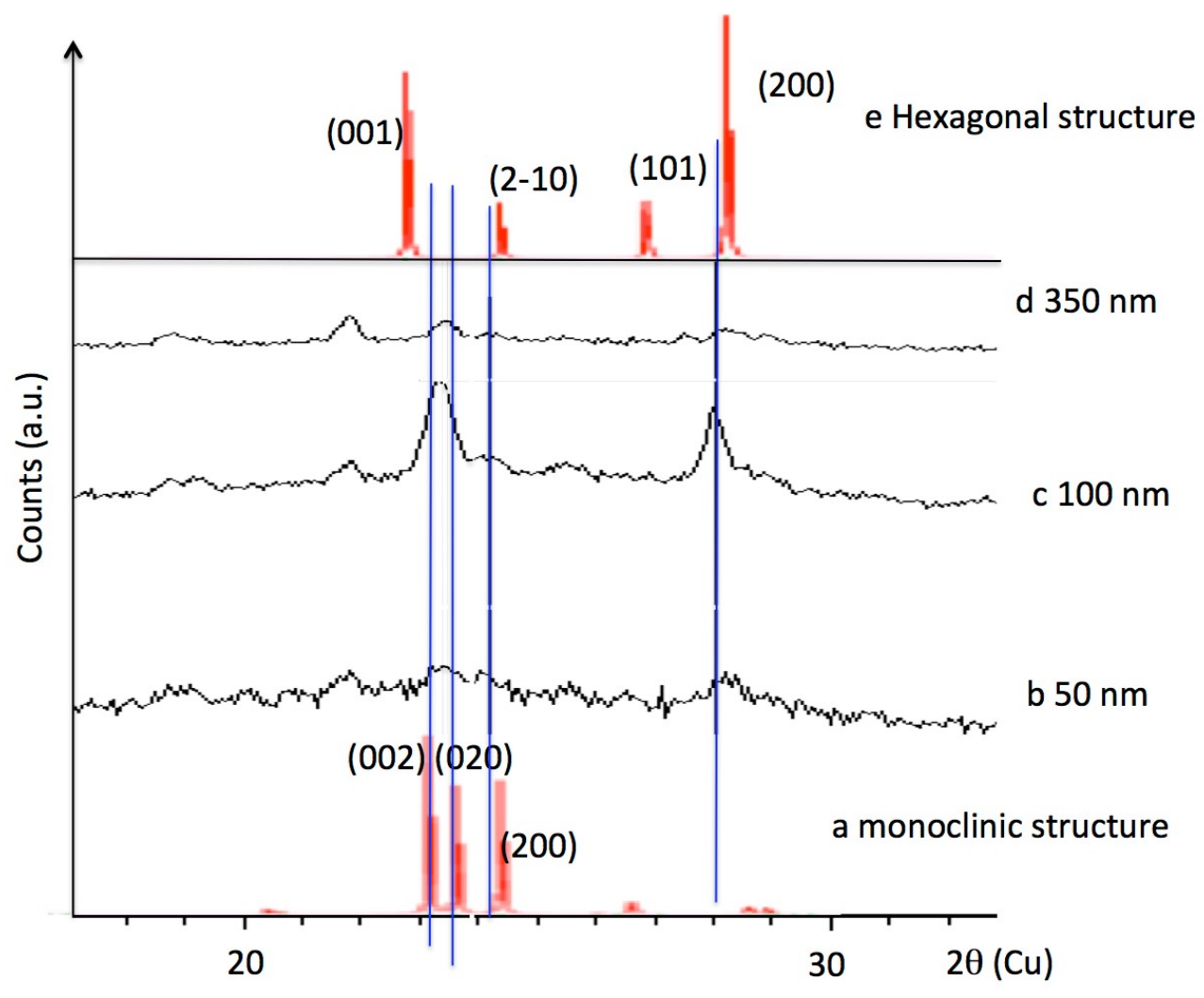

Figure S 2: XRD pattern of $\mathrm{WO}_{3}$ oxide films on $\mathrm{Au}$ with different thicknesses $(\mathrm{b}, \mathrm{c}, \mathrm{d})$ and annealed $350^{\circ} \mathrm{C}$. a and e correspond to references 3 and 4 . 


\section{Height of oxide nanostructures}

We show in Fig. S3a an STM image of a sample area containing S1, S2 and S3 nanostructures. The linescan in Fig. S3b shows the height of the 3 structures. Since the STM topography includes electronic effects, the apparent height does not give the exact structural height and therefore it does not allow to determine precisely the number of oxide layers. In order to obtain a rough estimation, we consider a ideal cubic lattice of $\mathrm{WO}_{3}$ with a lattice parameter of $3.84 \AA .^{5}$ The interlayer distance between the (111) planes in that case is $2.2 \AA$. Since all structures have a height below $1.2 \mathrm{~nm}$, it can be estimated that the oxide structures observed are made of no more than about 5 layers. As a rough estimate, the structure S1 can be of monolayer thick, the structure S2 can be made of 2 or 3 layers and S3 is most likely made of 4 or 5 layers.

(a)

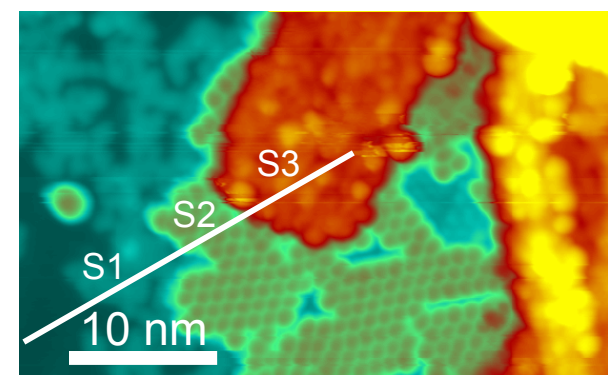

(b)

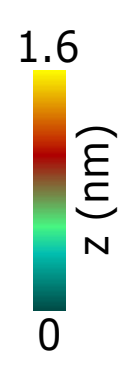

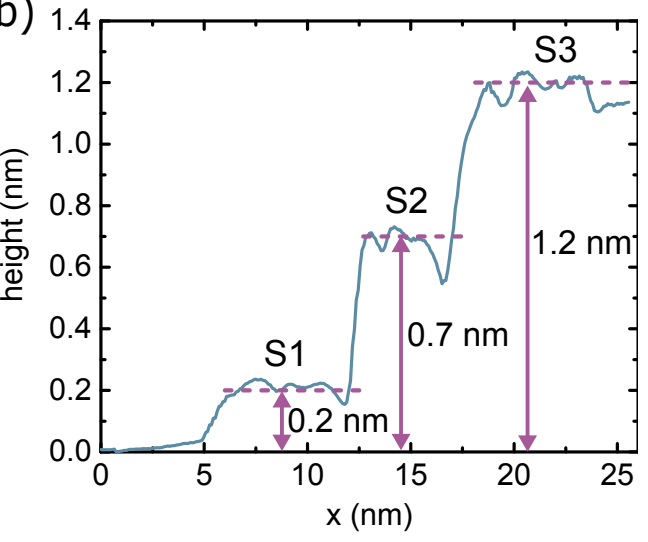

Figure S 3: (a) STM image of $\mathrm{WO}_{3}$ nanostructures on $\mathrm{Au}(111)$. (b) Linescan measured along the line indicated in (a).

\section{Orientation of the S2 nanostructure}

Figure 4 shows the S2 nanostructure together with the $\mathrm{Au}(111)$ reconstruction which consists

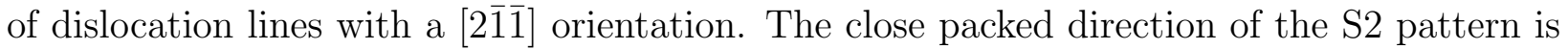
in the same direction as the dislocation lines which is rotated by 30 from the close packed direction of the $\mathrm{Au}(111)$ atomic lattice. Considering the periodicity of the $\mathrm{S} 2$ nanostructure 
$(0.95 \pm 0.05 \mathrm{~nm})$ and the periodicity of the $\mathrm{Au}(111)$ atomic lattice $(0.288 \mathrm{~nm})$ it can be concluded that the S2 structure has an epitaxial relationship with the $\mathrm{Au}(111)$ surface and forms a $2 \sqrt{3} \times 2 \sqrt{3}$ R30 layer. Note that the periodicity of the S2 nanostructure is close to the value obtained from the bulk parameters $(1.07 \mathrm{~nm}) .{ }^{4}$ The discrepancy between the two periodicities indicates that the epitaxy of $\mathrm{WO}_{3}$ on $\mathrm{Au}$ (111) with a lattice mismatch of around $10 \%$ may lead to strain at the interface of the two compounds.

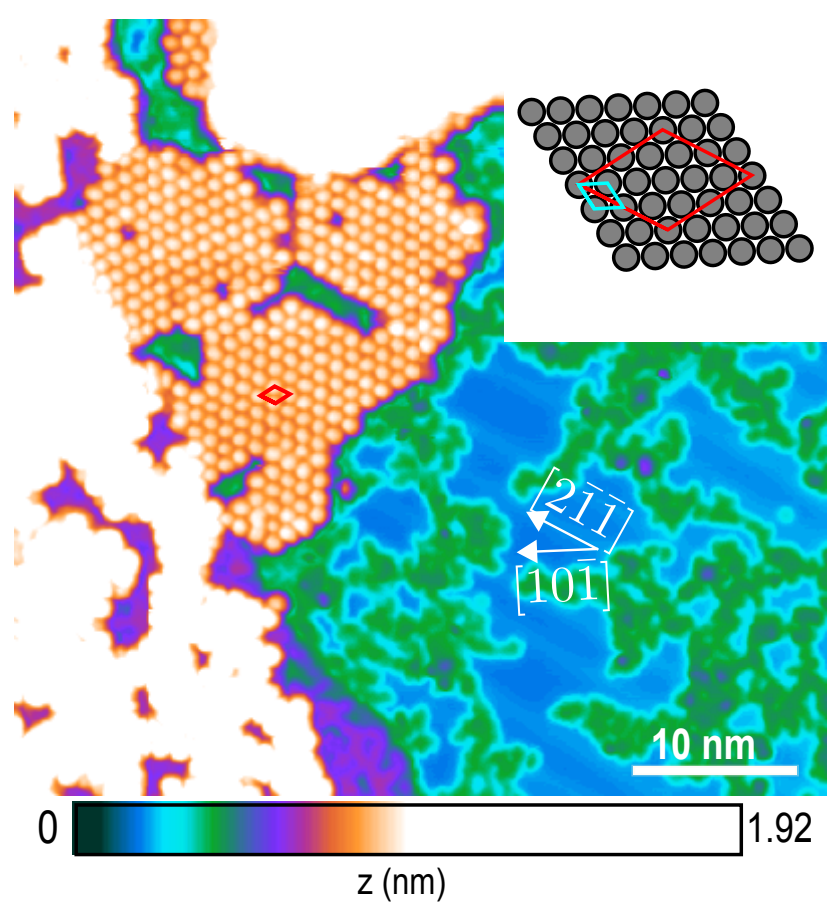

Figure S 4: STM image of the sample area shown in Fig. 3 with an enhanced contrast revealing the orientation of the $\mathrm{Au}(111)$ reconstruction. The unit cell of the S2 nanostructure is marked in red. The inset is a schematic representation of the $\mathrm{Au}(111)$ atomic lattice with the unit cells of $\mathrm{Au}(111)$ (in blue) and of the S2 nanostructure (in red).

\section{Optimized geometry of $\mathrm{WO}_{3}$ on $\mathrm{Au}(111)$}

Figure $\mathrm{S} 5$ shows the atomic structure of the $\mathrm{WO}_{3}$ on $\mathrm{Au}(111)$ complex used for the DFT calculations. 


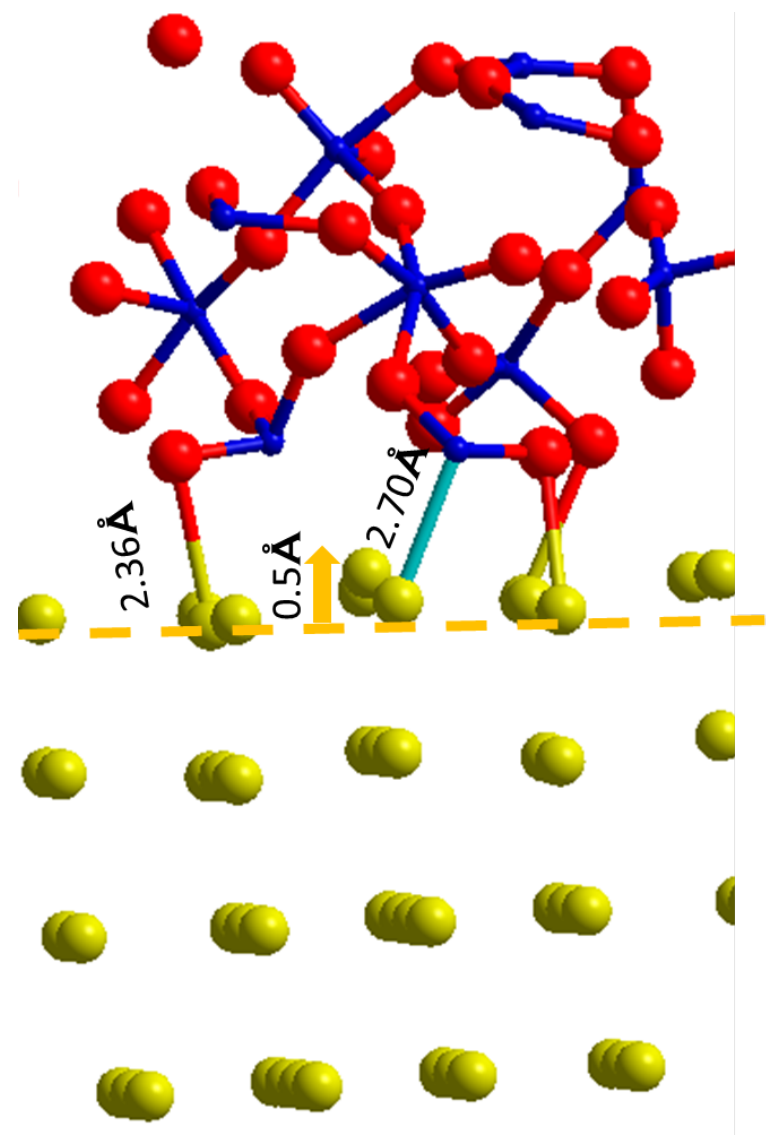

Figure S 5: Geometry of the $\mathrm{WO}_{3}$ on $\mathrm{Au}(111)$ structure used for DFT calculations. 


\section{References}

(1) Taylor, Z. N. et al. Stabilization of OO Bonds by d $d^{0}$ Cations in $\operatorname{Li}_{4+x} \mathrm{Ni}_{1 x} \mathrm{WO}_{6}(0 \leq \mathrm{x}$ $\leq 0.25)$ Rock Salt Oxides as the Origin of Large Voltage Hysteresis. J. Am. Chem. Soc. 2019, 141, 7333-7346.

(2) Díaz-Reyes, J.; Dorantes-García, V.; Pérez-Benítez, A.; Balderas-López, J. Obtaining of films of tungsten trioxide (WO3) by resistive heating of a tungsten filament. Superficies vacío 2008, 21, 12-17.

(3) Gerand, B.; Nowogrocki, G.; Guenot, J.; Figlarz, M. Structural study of a new hexagonal form of tungsten trioxide. J. Solid State Chem. 1979, 29, 429-434.

(4) Tanisaki, S. Crystal structure of monoclinic tungsten trioxide at room temperature. $J$. Phys. Soc. Jpn. 1960, 15, 573-581.

(5) Zheng, H.; Ou, J. Z.; Strano, M. S.; Kaner, R. B.; Mitchell, A.; Kalantar-zadeh, K. Nanostructured tungsten oxide-properties, synthesis, and applications. Adv. Funct. Mater. 2011, 21, 2175-2196. 